\title{
Article \\ ELISA-Based Analysis Reveals an Anti-SARS-CoV-2 Protein Immune Response Profile Associated with Disease Severity
}

\author{
Charline Herrscher ${ }^{1, *}$, Sébastien Eymieux ${ }^{1, *}$ (i) , Christophe Gaborit ${ }^{2}$, Hélène Blasco ${ }^{3}$, Julien Marlet ${ }^{1,4}(\mathbb{D}$, \\ Karl Stefic ${ }^{1,4}\left(\mathbb{D}\right.$, Philippe Roingeard ${ }^{1}$, Leslie Grammatico-Guillon ${ }^{1,2}{ }^{1}$ and Christophe Hourioux ${ }^{1}$ \\ 1 Inserm U1259 Morphogénèse et Antigénicité du VIH et des virus des Hépatites, Université de Tours et CHRU \\ de Tours, 37000 Tours, France; julien.marlet@univ-tours.fr (J.M.); karl.stefic@univ-tours.fr (K.S.); \\ philippe.roingeard@univ-tours.fr (P.R.); leslie.guillon@univ-tours.fr (L.G.-G.); \\ christophe.hourioux@univ-tours.fr (C.H.) \\ 2 Epidémiologie des Données Cliniques en Centre-Val de Loire (EpiDcliC), Centre Hospitalier Universitaire de \\ Tours, 37000 Tours, France; christophe.gaborit@univ-tours.fr \\ 3 Service de Biochimie et Biologie Moléculaire, CHRU de Tours, 37000 Tours, France; \\ helene.blasco@univ-tours.fr \\ 4 Service de Bactériologie-Virologie-Hygiène, CHRU de Tours, 37000 Tours, France \\ * Correspondence: charline.herrscher@etu.univ-tours.fr (C.H.); sebastien.eymieux@univ-tours.fr (S.E.)
}

Citation: Herrscher, C.; Eymieux, S.; Gaborit, C.; Blasco, H.; Marlet, J.;

Stefic, K.; Roingeard, P.;

Grammatico-Guillon, L.; Hourioux, C. ELISA-Based Analysis Reveals an Anti-SARS-CoV-2 Protein Immune Response Profile Associated with Disease Severity. J. Clin. Med. 2022, 11, 405. https://doi.org/10.3390/ jcm11020405

Academic Editors: Muh-Shi Lin and Andrew Chih Wei Huang

Received: 14 December 2021

Accepted: 11 January 2022

Published: 14 January 2022

Publisher's Note: MDPI stays neutral with regard to jurisdictional claims in published maps and institutional affiliations.

Copyright: (C) 2022 by the authors. Licensee MDPI, Basel, Switzerland. This article is an open access article distributed under the terms and conditions of the Creative Commons Attribution (CC BY) license (https:// creativecommons.org/licenses/by/ $4.0 /)$.

\begin{abstract}
Since the start of the COVID-19 pandemic, many studies have investigated the humoral response to SARS-CoV-2 during infection. Studies with native viral proteins constitute a first-line approach to assessing the overall immune response, but small peptides are an accurate and valuable tool for the fine characterization of B-cell epitopes, despite the restriction of this approach to the determination of linear epitopes. In this study, we used ELISA and peptides covering a selection of structural and non-structural SARS-CoV-2 proteins to identify key epitopes eliciting a strong immune response that could serve as a biological signature of disease characteristics, such as severity, in particular. We used 213 plasma samples from a cohort of patients well-characterized clinically and biologically and followed for COVID-19 infection. We found that patients developing severe disease had higher titers of antibodies mapping to multiple specific epitopes than patients with mild to moderate disease. These data are potentially important as they could be used for immunological profiling to improve our knowledge of the quantitative and qualitative characteristics of the humoral response in relation to patient outcome.
\end{abstract}

Keywords: SARS-CoV-2 antibodies; SARS-CoV-2 linear epitopes; COVID-19; disease severity

\section{Introduction}

In December 2019, cases of atypical pneumonia were reported in Wuhan, China. The unknown etiologic agent was later identified as a new coronavirus displaying $79.6 \%$ of genomic sequence identity to the severe acute respiratory syndrome coronavirus (SARSCoV) [1]. In March 2020, the World Health Organization (WHO) declared that coronavirus induced disease 2019 (COVID-19) was a global pandemic. During the first 24 months of the pandemic, there have been more than 280 million laboratory-confirmed cases of COVID-19 with over five million deaths.

Severe acute respiratory syndrome coronavirus-2 (SARS-CoV-2) is an enveloped, single-stranded positive sense RNA virus from the genus Betacoronavirus [2]. The main manifestations of SARS-CoV-2 infection include respiratory symptoms, systemic inflammation leading to multi-organ dysfunction, such as acute respiratory distress syndrome, cardiovascular disorders and neurological symptoms [3-6]. SARS-CoV-2 is more contagious than SARS-CoV, its greater transmissibility possibly being due to the larger number of asymptomatic patients with a high viral load [7]. The viral genome encodes four main structural proteins—spike (S), envelope (E), membrane (M) and nucleocapsid (N)—essential 
for virion assembly and infection. Spike is the outermost protein on the surface of the virus. It contains a receptor-binding domain (RBD) that interacts with the host receptor, angiotensin-converting enzyme 2 (ACE2), to mediate viral entry into cells [8]. The $\mathrm{M}$ protein is the most abundant structural protein of SARS-CoV-2 and is able to bind all the other structural proteins. Its function remains incompletely understood, but the binding of $\mathrm{M}$ protein has been shown to stabilize the $\mathrm{N}$ protein and to foster viral assembly by stabilizing the N protein-RNA complex [9]. The E protein is the smallest of the structural proteins playing an important role in virus assembly, release and virulence [10]. The $\mathrm{N}$ protein is highly conserved, with an amino-acid sequence $90 \%$ identical to that of the SARS-CoV nucleocapsid [11]. The N protein packages the RNA of the viral genome and participates in virion assembly through its interaction with the $\mathrm{M}$ protein [12]. The $\mathrm{N}$ proteins of many coronaviruses are highly immunogenic and produced in abundance in virus-infected cells [13].

Much attention has been devoted to identifying the immunodominant linear epitopes on SARS-CoV-2 proteins since the start of the outbreak. These epitopes are important for diagnosis, for the development of monoclonal antibodies for prevention and treatment, and for the design of peptide-based vaccines [14-16]. Several immunodominant linear epitopes have been identified on the S, M, E, N (for review [17]) and ORF8 [18] proteins. However, only a few studies have investigated the possible correlation between specific reactivity to particular linear epitopes and disease severity [19-21]. Such correlations may provide important information about the pathogenesis of SARS-CoV-2 infection and are of potential utility for patient stratification in medical practice. In this study, we performed bioinformatics analysis to predict antigenic linear epitopes in the $S, M, N$ and ORF8 proteins, which we then used to establish peptide-based ELISAs for use on plasma samples from COVID-19 patients and controls. We then investigated the correlations between severity and reactivity to several of the epitopes identified.

\section{Materials and Methods}

\subsection{Design and Participants}

We performed a cross-sectional study of patients testing positive for SARS-CoV-2 by RT-PCR during their hospitalization at Tours Regional University Hospital (Loire Valley, France) between 1 April 2020 and 1 July 2021. We analyzed plasma samples collected from these patients $25-35$ days after symptom onset. We excluded: (i) patients who refused to participate (ii) patients for whom no clinical data were available and (iii) patients with incomplete biological data.

\subsection{Clinical Variables of Interest}

The outcomes for the study population were analyzed according to patient characteristics, including sociodemographic factors (age, sex) and comorbid conditions (cardiovascular disease, hypertension, diabetes mellitus, lung disease, renal insufficiency, dialysis, kidney transplantation, liver failure and obesity). Participants were classified into three groups (mild, moderate and severe) according to the WHO COVID-19 classification of cases [22].

\subsection{Linear B-Cell Epitope Prediction}

We used the primary sequences of the $S, N, M$ and ORF8 proteins from the original (Wuhan) SARS-CoV-2 strain and the Bepipred-2.0 prediction module (https://services. healthtech.dtu.dk/service.php?BepiPred-2.0, accessed on 13 December 2021) to identify likely B-cell linear epitopes in these proteins [23]. The epitope threshold value was set at 0.55. We also used the Ellipro Antibody epitope prediction tool (http://tools.iedb.org/ ellipro/, accessed on 13 December 2021) [24] with the 3D structure prediction files for the $S$ protein (PDB ID: 6VXX and 6VSB), the N-terminal domain of the $\mathrm{N}$ protein (PDB ID: 7CDZ) and the ORF 8 protein (PDB ID: 7JX6) to identify complementary B-linear epitopes, and for the formal exclusion of conformational epitopes from our peptide set. We also excluded predicted sequences covering a predicted N-glycosylation site in the S protein, 
because chemical synthesis does not allow the addition of these glycosylated motifs to the peptide sequence. Long sequences predicted to be linear epitopes were split into peptides overlapping by five amino acids. Finally, based on the high degree of sequence identity between the SARS-CoV and SARS-CoV-2 N proteins, we were able to confirm our $\mathrm{N}$ peptide set on the basis of experimental determination of peptide reactivity in a SARS-CoV peptidebased ELISA described in a previous study [25]. N proteins display significant conservation among human coronaviruses. We therefore limited cross-reactivity with antibodies against commonly circulating human coronaviruses by aligning the sequences of the SARS-CoV-2 nucleocapsid and its homologs in HCoV-HUK1, HCoV-OC43, HCoV-NL63 and HCoV-229E, to identify immunogenic peptides with the lowest degree of similarity.

\subsection{Linear Peptide Library}

Based on Bepipred predictions, we had 60 linear peptides (19-38 residues) synthesized (Proteogenix, Schiltigheim, France) (Table S1). Forty-six peptides (SK1 to SK39) based on the primary sequence of the $S$ protein were synthesized. Ten linear peptides (NC1 to NC8) were synthesized for the $\mathrm{N}$ protein, and one peptide was synthesized for the $\mathrm{M}$ protein. Three peptides (NS1 to NS3) were synthesized based on the sequence of the ORF8 protein. This set of peptides included some peptides covering two versions of the same region. Peptide names ending in an apostrophe correspond to an extended version of the peptide to which 10 additional amino acids were added relative to the native peptide, equally distributed between the N-terminal and C-terminal parts of the molecule. A scrambled peptide (SK36) was used as the blank. The synthetic peptides were then purified by reverse-phase HPLC $(>80 \%$ purity), with verification of their molecular weight by mass spectrometry. The purified peptides were then dissolved to generate a $1 \mathrm{mg} / \mathrm{mL}$ solution, in accordance with the manufacturer's instructions, for storage at temperature below $-20^{\circ} \mathrm{C}$.

\subsection{Peptide-Base ELISA}

Synthesized peptides were prepared in sterile phosphate-buffered saline (PBS, Thermo Fisher Scientific, Waltham, MA, USA) at a final concentration of $3000 \mathrm{ng} / \mathrm{mL}$. Nunc Maxisorp 96-well immunoassay plates (Thermo Fisher Scientific) were coated by overnight incubation at $4{ }^{\circ} \mathrm{C}$ with $100 \mu \mathrm{L}$ of prepared peptides per well. The plates were washed three times with a plate washer. The washing solution (PBST) used for all washes was composed PBS supplemented with $0.1 \%$ Tween-20 (Sigma Aldrich, St. Louis, MO, USA). The plates were then blocked by incubation with $3 \%$ non-fat dry milk (NFDM) prepared in PBS at room temperature for $1 \mathrm{~h}$. The plates were washed once and $100 \mu \mathrm{L}$ of diluted $(1: 50$ in $1 \%$ NFDM prepared in PBST) human plasma were added per well. Then plates were incubated at room temperature for $30 \mathrm{~min}$, washed six times with washing solution and incubated at room temperature for $30 \mathrm{~min}$ with $100 \mu \mathrm{L}$ horseradish peroxidase (HRP)-labeled mouse anti-human IgG Fcy-specific antibody (Southern Biotech, Birmingham, AL, USA) diluted $1: 10,000$ in $1 \%$ NFDM prepared in PBST. The plates were washed six times and incubated with $100 \mu \mathrm{L}$ developing solution per well (Sigma Fast OPD, Sigma Aldrich) for $10 \mathrm{~min}$ in the dark at room temperature. The reaction was stopped by adding $100 \mu \mathrm{L} 2 \mathrm{~N} \mathrm{H}_{2} \mathrm{SO}_{4}$ per well and absorbance was measured on a microplate reader at $490 \mathrm{~nm}$, with $630 \mathrm{~nm}$ as the reference wavelength.

\subsection{Peptides of Interest}

We pooled 50 different pre-pandemic plasma samples collected before January 2018, to constitute a pooled negative control (unrelated to the COVID-19 patients further investigated in our study). We first used 50 plasma samples randomly selected from the COVID-19 patients described above for the selection of peptides of interest. Briefly, all plasma samples (negative controls and samples from COVID-19 patients) were tested in duplicate against the whole set of synthesized peptides using ELISA assay. 


\subsection{Statistical Analysis}

The continuous variables are expressed as the mean \pm standard deviation (SD), whereas the qualitative variables are expressed as absolute numbers and percentages. Peptide OD values were initially studied as continuous variables, but sensitivity analyses were performed to assess the value of treating peptide $\mathrm{OD}$ as a qualitative variable with a relevant threshold identified from ROC curves and graphical presentations. An optimal cut-off value was identified for each peptide. Each cut-off has been chosen accordingly to the best balance between odds ratio of severity and its $p$-value. We proposed a graphical plot that illustrates the OD ability to classify the COVID-19 disease as severe according to the variations in the OD value distribution, giving a discrimination threshold = cut-off (on the same basis as ROC curves) (Supplementary Data Figure S1). For the identification of factors associated with severity, we first performed bivariate analyses with the variables of interest, including the OD for each peptide, clinical and sociodemographic variables, in univariate logistic regression models. We then performed multiple logistic regression, including variables for which $p<0.2$ in the model, together with variables considered clinically relevant. A descending stepwise process was used to select the final linear regression model. The odd ratios (ORs) and 95\% CIs were estimated for an association between COVID-19 severity and biological outcomes, including the OD of each peptide as a binary variable with a threshold/cut-off chosen on the basis of OD distribution and OR.

All tests were two-tailed, and $p$ values below 0.05 were considered statistically significant. We included all participants for whom the variables of interest were available in the final analysis, without imputing missing data. All statistical analysis were performed with SAS, version 9.4, with SAS Enterprise Guide 71 64-bit (SAS Institute Inc., Cary, NC, USA).

\subsection{Ethics Approval}

This study involved the reuse of data that had already been recorded. It falls within the scope of the French Research Commission according to the 2016-41 law of 26 January 2016 on the modernization of the French health system (DC 2020_097), according to which written informed consent is required from all individuals included in biomedical studies. Samples were obtained from the registered biological collection DC-2020-3961.

\section{Results}

\subsection{Characteristics of Participants}

During the study period, we obtained 213 plasma samples from SARS-CoV-2 positive patients for whom complete clinical and biological data were available, and who had given consent for participation. The sociodemographic and clinical characteristics of the participants are shown in Table 1.

The median age of the participants was 69 (55-84) years, with a sex ratio of 0.85 (99 (46\%) men and 114 (54\%) women). The most common comorbid condition was hypertension (109 patients, $51 \%$ ), followed by cardiovascular diseases (76 patients, $35 \%$ ), obesity (52 patients, $24 \%$ ) and diabetes mellitus (44 patients, 21\%). Eighty-four patients (39\%) had mild infections, 42 patients (20\%) developed moderate infections and 87 participants $(41 \%)$ were admitted to the intensive care unit (ICU) due to severe infection. Among patients developing mild infections, the main comorbid condition was hypertension (34\%), followed by cardiovascular diseases $(25 \%)$ and diabetes mellitus $(20 \%)$. The proportion of women was higher than the proportion of men in the group of patients with mild infection (68\% versus $32 \%$ in men). The most frequent comorbid factors in patients with moderate infection were hypertension (60\%), cardiovascular diseases (43\%) and obesity (24\%). The other comorbid conditions were evenly distributed between disease severity groups (around 20\% in each group). The proportion of women was higher than the proportion of men in the group of patients with moderate infections (64\% versus $36 \%$ in men). Among patients admitted to the ICU, the percentage of patients with comorbidity factors was high, whatever the comorbid conditions considered. Hypertension (63\%), cardiovascular disease $(42 \%)$ and obesity were the most common comorbid conditions. The proportion of men 
was higher than the proportion of women in the severe infection group $(66 \%$ versus $34 \%$ in women).

Table 1. Characteristics of the patients included.

\begin{tabular}{ccccc}
\hline Clinical Data & \multicolumn{4}{c}{ Disease Severity } \\
& Mild & Moderate & Severe & Total \\
& $\mathbf{N ~ ( \% )}$ & $\mathbf{N ~ ( \% )}$ & $\mathbf{N ~ ( \% )}$ & $\mathbf{N ~ ( \% )}$ \\
& $\mathbf{8 4}(\mathbf{3 9 )}$ & $\mathbf{4 2 ( 2 0 )}$ & $\mathbf{8 7 ~ ( 4 1 )}$ & $\mathbf{2 1 3}(\mathbf{1 0 0})$ \\
\hline Median age (interquartile range) & 65 & 83.5 & 69 & 69.0 \\
(years) & $(45.7-87.0)$ & $(58.5-89.5)$ & $(61.0-75.0)$ & $(55.0-84.0)$ \\
Male & $27(32)$ & $15(36)$ & $57(66)$ & $99(46)$ \\
Female & $57(68)$ & $27(64)$ & $30(34)$ & $114(54)$ \\
Cardiovascular disease & $21(25)$ & $18(43)$ & $37(42)$ & $76(35)$ \\
Hypertension & $29(34)$ & $25(60)$ & $55(63)$ & $109(51)$ \\
Diabetes mellitus & $17(20)$ & $9(21)$ & $18(21)$ & $44(21)$ \\
Lung disease & $10(12)$ & $6(14)$ & $17(19)$ & $33(16)$ \\
Renal insufficiency & $5(6)$ & $7(17)$ & $9(10)$ & $21(10)$ \\
Dialysis & $0(0.0)$ & $0(0)$ & $1(1)$ & $1(0.5)$ \\
Kidney transplantation & $0(0.0)$ & $1(2)$ & $4(5)$ & $5(2)$ \\
Liver failure & $4(5)$ & $0(0)$ & $1(1)$ & $5(2)$ \\
Obesity & $12(14)$ & $10(24)$ & $30(34)$ & $52(24)$ \\
\hline
\end{tabular}

Data are absolute numbers (\%) or medians (interquartile range).

\subsection{Selecting the Peptides of Interest}

Our peptide mapping identified several hotspots in the SARS-CoV-2 proteins covered (Figure 1). In this first set of ELISAs, peptides giving a mean optical density (OD) greater than 0.3 and at least five times higher than the OD obtained with the negative control were selected for further analysis (Table S2).

COVID + - Mean Pool COVID - $\quad$ - Mean COVID +

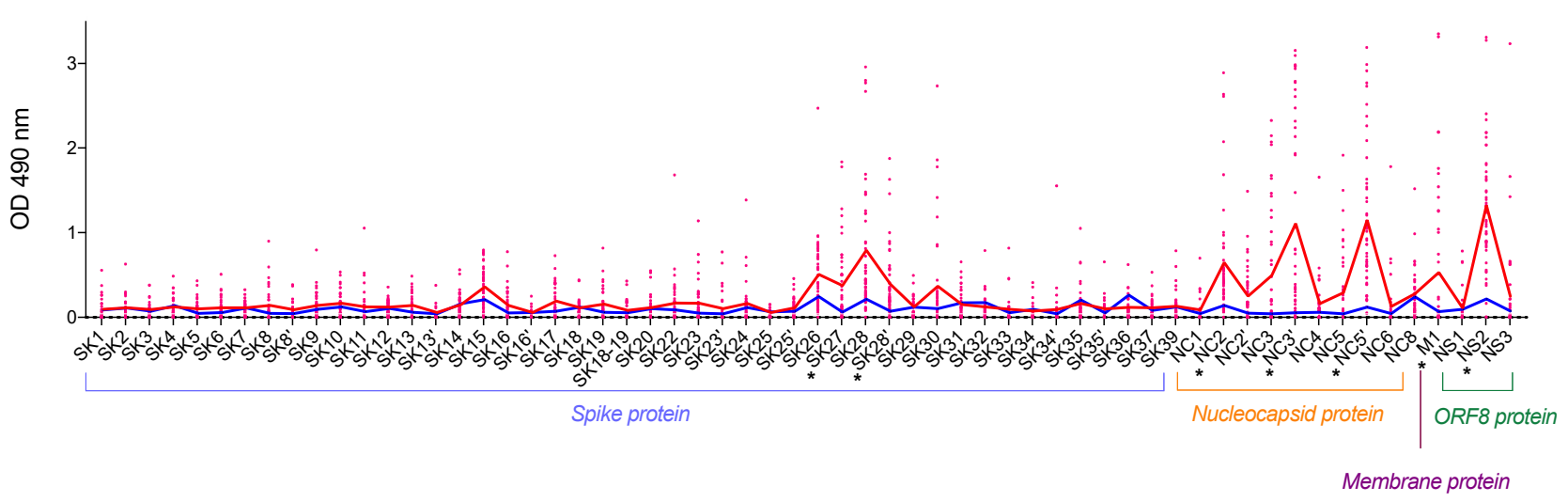

Figure 1. Identification of IgG-specific B-cell epitopes on the spike (S), nucleocapsid (N), membrane (M) and ORF8 proteins. We pooled 50 pre-pandemic plasma samples collected before January 2018 to constitute a COVID-19 negative control (Pool COVID-). We used 50 plasma samples from patients tested positive for SARS-CoV-2 by RT-PCR, collected between 25 and 35 days after the onset of symptom, to evaluate IgG reactivity to 60 peptides. OD results are represented for each sample as a pink point for COVID+ samples. The red line represents the mean OD for COVID+ patients and the blue line represents the mean OD of 50 repeated measures for the COVID- pool. * indicates the peptides selected for further analysis.

For the $S$ protein, at least one region was found to constitute a B-cell epitope. This region was covered by peptides SK27 and SK28. The mean OD obtained with SK27 was 0.335 for COVID+ versus 0.024 for the COVID- pool. For SK28, the mean OD for COVID+ samples was 0.748 and that for the COVID- pool was 0.175. Peptide reactivity was greater 
for the $\mathrm{N}$ protein than for the $\mathrm{S}$ protein. Three peptides reacted strongly with COVID+ samples: NC2, NC3' and NC5'. Mean OD was 0.605 for NC2 vs. 0.101 for the COVID- pool, 1.063 for $\mathrm{NC}^{\prime}$ vs. 0.017 for the COVID- pool and 1.103 for $\mathrm{NC}^{\prime}$ vs. 0.082 for the COVIDpool. The single peptide obtained from the $\mathrm{M}$ protein showed also displayed a large difference in reactivity between the COVID+ and COVID- pool samples (0.489 vs. 0.032, respectively). For ORF8, only one peptide was highly reactive with COVID+ samples: NS2, with a mean OD of 1.275 , versus 0.176 for the COVID- pool. We therefore selected the following peptides (SK27, SK28, NC2, NC3' ${ }^{\prime} \mathrm{NC}^{\prime}, \mathrm{M} 1$ and NS2) for the next step of the study.

\subsection{Analysis of the Selected Peptides}

We analyzed antibody responses to selected peptides according to disease severity. The median OD and interquartile range for each peptide are shown in Table 2, and a boxplot for each peptide against disease severity is shown in Figure 2.

Table 2. IgG response to selected peptides.

\begin{tabular}{cccc}
\hline Peptides of Interest & Mild & Disease Severity & \\
\hline & $0.015(0.000-0.065)$ & $0.001(0.000-0.1375)$ & $0.342(0.073-0.851)$ \\
SK27 & $0.138(0.043-0.293)$ & $0.124(0.023-0.716)$ & $0.591(0.161-1.48)$ \\
SK28 & $0.237(0.065-0.458)$ & $0.273(0.123-0.513)$ & $0.432(0.235-0.865)$ \\
NC2 & $0.068(0.005-0.649)$ & $0.236(0.037-2.101)$ & $0.749(0.221-2.522)$ \\
NC3 & $0.532(0.169-1.097)$ & $0.662(0.332-1.440)$ & $1.052(0.502-2.298)$ \\
NC5 & $0.000(0.000-0.235)$ & $0.000(0.000-0.085)$ & $0.130(0.000-1.012)$ \\
M1 & $0.512(0.072-1.216)$ & $0.801(0.476-1.319)$ & $0.811(0.467-1.138)$ \\
NS2 &
\end{tabular}

Data are expressed as the median (interquartile range).

These results suggest that the IgG response to selected epitopes, other than NS2, was stronger in patients with severe COVID-19 than in those with mild or moderate disease. Indeed, for every peptide other than NS2, the median value increased with disease severity. Large differences between groups were observed for some epitopes. Reactivity to the M1 peptide differed considerably between the mild, moderate and severe COVID-19 groups (Figure 2). By contrast, there was little difference between the groups in terms of reactivity to the NC2' peptide. For confirmation of these observations, we used logistic modeling to analyze the data, to identify clinical variables and peptides associated with disease severity.

\subsection{Analysis of Variables and Peptides Associated with Disease Severity}

We used ROC curves and graphical presentations to determine the optimal cut-off value for each peptide (Figure S1). We then analyzed the factors associated with the severity of SARS-CoV-2 infection. The results of this analysis are summarized in Table 3.

After adjustment, the analysis showed that a severe clinical presentation was more than three times more likely in patients over the age of 50 years (OR 3.5, 95\% CI 1.05-13.36); 2.7 times more likely in male patients (OR 2.7, 95\% CI 1.21-6.08) and 2.5 times more likely in patients with hypertension (OR 2.5, 95\% CI 1.03-6.15). The severe clinical presentation was significantly associated with high levels of IgG reactivity to the SK27, NC3 ${ }^{\prime}$ and M1 epitopes. Indeed, for OD values greater than 0.05 for SK27, the probability of having severe COVID-19 disease increased by $410 \%$; the risk of severe infection was, thus, more than four times higher (OR 4.1, 95\% CI 1.80-8.83). OD greater than 0.17 for NC3' was associated with an almost four times higher risk of patients presenting severe clinical outcomes. Similarly, an OD greater than 0.9 for the M1 epitope was associated with higher severity, with a risk of developing the severe form almost seven times higher than that for an OD value below this threshold (OR 6.9, 95\% CI 1.94-28.37). The probability of a severe COVID-19 outcome was four to seven times higher for values above the OD thresholds for SK27, NC3' and M1 peptides than for OD values below these thresholds. However, for NS2, an OD > 2 was 
associated with a $90 \%$ lower risk of the severe clinical presentation than OD values below this threshold.

Peptide SK27

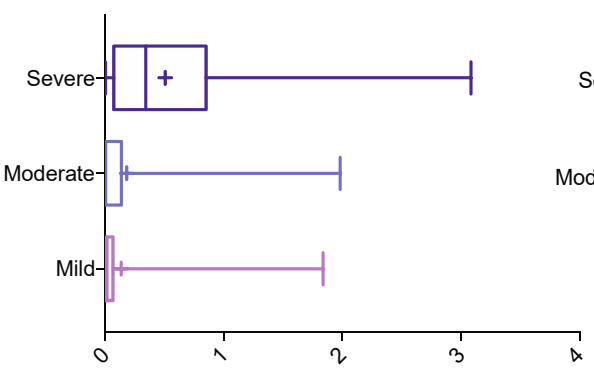

OD $490 \mathrm{~nm}$

Peptide NC3

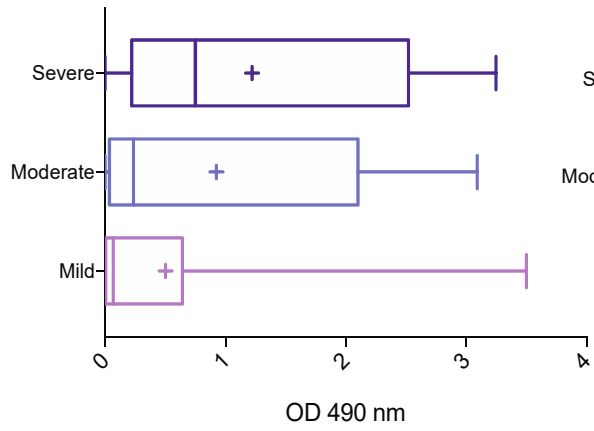

Peptide NS2

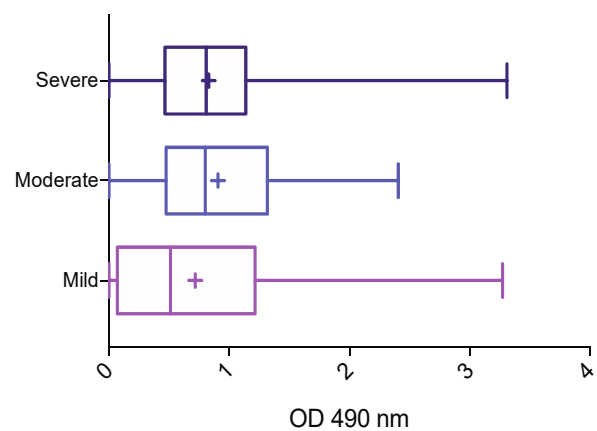

Figure 2. Association of epitope-specific IgG levels with disease severity. COVID-19 patients were classified on the basis of the clinical severity of disease (mild: $n=84$; moderate: $n=42$ and severe/ICU: $n=87)$.

Table 3. Clinical factors and B-cell epitopes associated with a severe clinical presentation, in multivariate logistic regressions analysis.

\begin{tabular}{cccccc}
\hline Variables of Interest & \multicolumn{2}{c}{ Univariate Analysis } & \multicolumn{3}{c}{ Multivariate Analysis } \\
\hline & Crude OR & $p$-Value & OR & 95\%CI & $p$-Value \\
\hline Clinical features & & & & & \\
Age $>50$ years & 6.1 & $<10^{-3}$ & 3.5 & $1.05-13.36$ & 0.049 \\
Male & 3.8 & $<10^{-3}$ & 2.7 & $1.21-6.08$ & 0.02 \\
Cardiovascular diseases & 1.6 & 0.09 & - & - & - \\
Hypertension & 2.3 & 0.003 & 2.5 & $1.03-6.15$ & 0.04 \\
\hline
\end{tabular}


Table 3. Cont.

\begin{tabular}{|c|c|c|c|c|c|}
\hline \multirow{2}{*}{$\begin{array}{l}\text { Variables of Interest } \\
\text { Chronic lung diseases }\end{array}$} & \multicolumn{2}{|c|}{ Univariate Analysis } & \multicolumn{3}{|c|}{ Multivariate Analysis } \\
\hline & 1.6 & 0.18 & - & - & - \\
\hline Diabetes mellitus & 1.0 & 0.98 & - & - & - \\
\hline Obesity & 2.6 & 0.01 & - & - & - \\
\hline Kidney chronic diseases & 1.1 & 0.85 & - & - & - \\
\hline Liver failure & 0.4 & 0.35 & - & - & - \\
\hline \multicolumn{6}{|l|}{ Peptides } \\
\hline SK27 > 0.05 & 7.4 & $<10^{-3}$ & 4.1 & $1.80-9.83$ & $<10^{-3}$ \\
\hline SK28 > 0.3 & 2.6 & $<10^{-3}$ & - & - & - \\
\hline $\mathrm{NC} 2>0.1$ & 4.2 & 0.001 & - & - & - \\
\hline $\mathrm{NC}^{\prime}>0.17$ & 4.9 & $<10^{-3}$ & 3.9 & $1.70-9.22$ & 0.002 \\
\hline $\mathrm{NC}^{\prime}>0.35$ & 3.4 & 0.001 & - & - & - \\
\hline $\mathrm{M} 1>0.9$ & 9.1 & $<10^{-3}$ & 6.9 & $1.94-28.37$ & $<10^{-3}$ \\
\hline NS2 $>2$ & 0.1 & 0.06 & 0.1 & $0.002-0.63$ & 0.03 \\
\hline
\end{tabular}

\section{Discussion}

Many studies have been performed to identify B-cell linear epitopes in the SARSCoV-2 proteins [18,19,26-37]. Our study confirms previous findings, identifying the same overall regions. Surprisingly, only two epitopes were found on the S protein, located within the S1/S2 subdomain. No IgG response to peptide covering the receptor binding domain (RBD) was detected, despite this region being known to be highly immunogenic [38]. However, previous studies have reported similar results, suggesting that the RBD is rich in conformational epitopes but lacks linear epitopes [20]. In addition, we cannot exclude non-detection of peptide reactivity in our ELISA approaches, due to the short length of the peptides or their low efficiency to be adsorbed on the plates.

This study focused particularly on the possible association between disease severity and IgG response to these linear epitopes that could be analyzed by ELISA. The clinical factors associated with disease severity and mortality in COVID-19 patients have been studied in detail since the start of the pandemic. The clinical data for our patients are consistent with those reported in other studies, demonstrating that increasing age, being male, dyspnea, diabetes, hypertension, and obesity are associated with disease severity [39-41]. The magnitude of the humoral response is highly variable and has been shown to be positively correlated with disease severity [42]. Only two studies have described the epitopes eliciting this strong IgG response linked to severe clinical outcomes $[19,28]$. Both these studies identified immunodominant epitopes within the $S$ and $N$ proteins. We identified the same epitopes in our analysis, together with an additional epitope on the M protein, for which a strong humoral response was strongly correlated with disease severity. Indeed, we found that the IgG response elicited by the M1 epitope was responsible for the largest difference between disease severity groups. Patients with mild-to-moderate COVID-19 had weak antibody responses to M1, whereas patients with severe clinical presentations had very strong IgG responses to M1 (OR 6.9, 95\% CI 1.94-28.37). Finally, we also analyzed the predicted B-cell linear epitopes of ORF8. We identified one epitope that elicited a strong humoral response in patients infected with SARS-CoV-2. ORF8 was recently identified as a novel secreted protein absent from all human pathogenic coronaviruses except SARS-CoV-2 [43]. It has been suggested that ORF8 plays a biological role in the pathogenesis of SARS-CoV-2, by mediating immune evasion via the downregulation of MHC-I molecules [44]. We therefore investigated whether patients with different severities of COVID-19 had different IgG responses to an epitope (NS2) identified in ORF8. We found large differences in reactivity between groups for this particular epitope. Logistic modeling revealed that the risk of developing severe COVID-19 decreased by $90 \%$ above the NS2 cut-off. However, the established cut-off is very high (OD > 2), suggesting that the $\operatorname{IgG}$ response was strong regardless of clinical presentation. This observation confirms that ORF8 is a unique and specific protein secreted by SARS-CoV-2. Our results suggest that 
patients with severe clinical outcomes have a weaker IgG response to ORF8 than patients with mild-to-moderate COVID-19 disease. We therefore provide new data for the NS2 epitope of the ORF8 protein, and describe a new epitope, M1, linked to COVID-19 severity. One limitation of this study is that we considered only short peptides. Longer peptides, which may retain some conformational information, may be more informative. However, the use of longer peptides would decrease the precision of identification for the epitopes involved. Another limitation of this study is that we could not have repetitions for all patients because of the restricted amount of plasma. However, when possible, plasma were tested in duplicate and OD obtained were very similar. In addition, a much larger cohort of COVID-19 patients with mild, moderate and severe disease will be required to strengthen these data.

The identification of serological markers of COVID-19 severity is an important goal, as it would facilitate profiling, making it possible to determine how viral responses differ between patients with different outcomes. The IgG response has been shown to be correlated with severity. This positive correlation raised the possibility that antibody-dependent enhancement (ADE) could, in some instances, contribute to the excessive immune response that exacerbates SARS-CoV-2 pathogenesis [45,46]. In this context, further studies on the immune response to the M1 and NS2 epitopes identified here will be useful, to determine the potential role of these epitopes in the immunopathogenicity of SARS-CoV-2 infection. Should these epitopes prove useful as clinical biomarkers of disease severity, ELISA-based assays would clearly be a valuable tool for monitoring them.

Supplementary Materials: The following supporting information can be downloaded at: https: / / www.mdpi.com/article/10.3390/jcm11020405/s1, Figure S1: Graphic determination of optimal OD cut-off for each peptide, Table S1: Peptide sequences of putative immunodominant SARS-CoV-2 IgG linear B-cell epitopes, Table S2: Peptides of interest: selection.

Author Contributions: Conceptualization, C.H. (Christophe Hourioux) and S.E.; Methodology, C.H. (Charline Herrscher) and S.E.; Software, C.H. (Christophe Hourioux), C.H. (Charline Herrscher) and S.E.; Validation, C.H. (Christophe Hourioux), C.H. (Charline Herrscher) and S.E.; Formal analysis, C.G. and L.G.-G.; Investigation, C.H. (Charline Herrscher), C.G. and L.G.-G.; Resources, C.H. (Charline Herrscher), J.M., K.S., S.E. and H.B.; Data curation, S.E., K.S. and J.M.; Writing-original draft preparation, C.H. (Charline Herrscher); Writing-review and editing, S.E., C.H. (Christophe Hourioux), C.H. (Charline Herrscher), L.G.-G. and P.R.; Visualization, C.H. (Charline Herrscher); Supervision, P.R., C.H. (Christophe Hourioux) and S.E.; Project administration, C.H. (Christophe Hourioux); Funding acquisition, C.H. (Christophe Hourioux). All authors have read and agreed to the published version of the manuscript.

Funding: This research was funded by Agence Nationale de la Recherche, grant number ANR-20COVI-0011-01 and by the Centre-Val de Loire region, France, grant number 202000140687.

Institutional Review Board Statement: The study was conducted according to the guidelines of the Declaration of Helsinki, and approved by the Ethics Committee of the French research Commission (DC 2020_097, approved 26 January 2016).

Informed Consent Statement: Informed consent was obtained from all subjects involved in the study.

Data Availability Statement: The data presented in this study are available on request from the corresponding author. The data are not publicly available due to privacy issues.

Acknowledgments: We would like to acknowledge the virology, biochemistry, and occupational medicine services from Tours regional University hospital for their help to constitute the plasma collection of patients tested positive for SARS-CoV-2. We also would like to thank Philippe Despres for helpful discussion. Finally, we wish to thank Elena Angoulvant for her help with the initial development of ELISA conditions.

Conflicts of Interest: The authors declare no conflict of interest. 


\section{References}

1. Zhou, P.; Yang, X.-L.; Wang, X.-G.; Hu, B.; Zhang, L.; Zhang, W.; Si, H.-R.; Zhu, Y.; Li, B.; Huang, C.-L.; et al. A pneumonia outbreak associated with a new coronavirus of probable bat origin. Nature 2020, 579, 270-273. [CrossRef]

2. Chen, Y.; Liu, Q.; Guo, D. Emerging coronaviruses: Genome structure, replication, and pathogenesis. J. Med. Virol. 2020, 92, 418-423. [CrossRef]

3. Helms, J.; Kremer, S.; Merdji, H.; Clere-Jehl, R.; Schenck, M.; Kummerlen, C.; Collange, O.; Boulay, C.; Fafi-Kremer, S.; Ohana, M.; et al. Neurologic Features in Severe SARS-CoV-2 Infection. N. Engl. J. Med. 2020, 382, 2268-2270. [CrossRef]

4. Wang, D.; Hu, B.; Hu, C.; Zhu, F.; Liu, X.; Zhang, J.; Wang, B.; Xiang, H.; Cheng, Z.; Xiong, Y.; et al. Clinical Characteristics of 138 Hospitalized Patients With 2019 Novel Coronavirus-Infected Pneumonia in Wuhan, China. JAMA 2020, 323, 1061. [CrossRef] [PubMed]

5. Rowley, A.H.; Shulman, S.T.; Arditi, M. Immune pathogenesis of COVID-19-related multisystem inflammatory syndrome in children. J. Clin. Investig. 2020, 130, 5619-5621. [CrossRef] [PubMed]

6. Jiang, L.; Tang, K.; Levin, M.; Irfan, O.; Morris, S.K.; Wilson, K.; Klein, J.D.; Bhutta, Z.A. COVID-19 and multisystem inflammatory syndrome in children and adolescents. Lancet Infect. Dis. 2020, 20, e276-e288. [CrossRef]

7. Lu, S.; Xie, X.; Zhao, L.; Wang, B.; Zhu, J.; Yang, T.; Yang, G.; Ji, M.; Lv, C.; Xue, J.; et al. The immunodominant and neutralization linear epitopes for SARS-CoV-2. Cell Rep. 2021, 34, 108666. [CrossRef]

8. Wang, Q.; Zhang, Y.; Wu, L.; Niu, S.; Song, C.; Zhang, Z.; Lu, G.; Qiao, C.; Hu, Y.; Yuen, K.-Y.; et al. Structural and Functional Basis of SARS-CoV-2 Entry by Using Human ACE2. Cell 2020, 181, 894-904.e9. [CrossRef]

9. Astuti, I.; Ysrafil. Severe Acute Respiratory Syndrome Coronavirus 2 (SARS-CoV-2): An overview of viral structure and host response. Diabetes Metab. Syndr. Clin. Res. Rev. 2020, 14, 407-412. [CrossRef]

10. Chai, J.; Cai, Y.; Pang, C.; Wang, L.; McSweeney, S.; Shanklin, J.; Liu, Q. Structural basis for SARS-CoV-2 envelope protein recognition of human cell junction protein PALS1. Nat. Commun. 2021, 12, 3433. [CrossRef]

11. Grifoni, A.; Sidney, J.; Zhang, Y.; Scheuermann, R.H.; Peters, B.; Sette, A. A Sequence Homology and Bioinformatic Approach Can Predict Candidate Targets for Immune Responses to SARS-CoV-2. Cell Host Microbe 2020, 27, 671-680.e2. [CrossRef]

12. Bai, Z.; Cao, Y.; Liu, W.; Li, J. The SARS-CoV-2 Nucleocapsid Protein and Its Role in Viral Structure, Biological Functions, and a Potential Target for Drug or Vaccine Mitigation. Viruses 2021, 13, 1115. [CrossRef]

13. Dutta, N.K.; Mazumdar, K.; Gordy, J.T. The Nucleocapsid Protein of SARS-CoV-2: A Target for Vaccine Development. J. Virol. 2020, 94, e00647-20. [CrossRef] [PubMed]

14. Galipeau, Y.; Greig, M.; Liu, G.; Driedger, M.; Langlois, M.-A. Humoral Responses and Serological Assays in SARS-CoV-2 Infections. Front. Immunol. 2020, 11, 610688. [CrossRef]

15. Ahmad, T.A.; Eweida, A.E.; Sheweita, S.A. B-cell epitope mapping for the design of vaccines and effective diagnostics. Trials Vaccinol. 2016, 5, 71-83. [CrossRef]

16. Sawyer, L.A. Antibodies for the prevention and treatment of viral diseases. Antivir. Res. 2000, 47, 57-77. [CrossRef]

17. Farrera-Soler, L.; Daguer, J.-P.; Barluenga, S.; Winssinger, N. Experimental Identification of Immuno-dominant B-cell Epitopes from SARS-CoV-2. Chimia 2021, 75, 276-284. [CrossRef]

18. Wang, X.; Lam, J.-Y.; Chen, L.; Au, S.W.-N.; To, K.K.W.; Yuen, K.-Y.; Kok, K.-H. Mining of linear B cell epitopes of SARS-CoV-2 ORF8 protein from COVID-19 patients. Emerg. Microbes Infect. 2021, 10, 1016-1023. [CrossRef]

19. Amrun, S.N.; Lee, C.Y.-P.; Lee, B.; Fong, S.-W.; Young, B.E.; Chee, R.S.-L.; Yeo, N.K.-W.; Torres-Ruesta, A.; Carissimo, G.; Poh, C.M.; et al. Linear B-cell epitopes in the spike and nucleocapsid proteins as markers of SARS-CoV-2 exposure and disease severity. EBioMedicine 2020, 58, 102911. [CrossRef]

20. Li, Y.; Ma, M.; Lei, Q.; Wang, F.; Hong, W.; Lai, D.; Hou, H.; Xu, Z.; Zhang, B.; Chen, H.; et al. Linear epitope landscape of the SARS-CoV-2 Spike protein constructed from 1051 COVID-19 patients. Cell Rep. 2021, 34, 108915. [CrossRef]

21. Schwarz, T.; Heiss, K.; Mahendran, Y.; Casilag, F.; Kurth, F.; Sander, L.E.; Wendtner, C.-M.; Hoechstetter, M.A.; Müller, M.A.; Sekul, R.; et al. SARS-CoV-2 Proteome-Wide Analysis Revealed Significant Epitope Signatures in COVID-19 Patients. Front. Immunol. 2021, 12, 629185. [CrossRef]

22. Marshall, J.C.; Murthy, S.; Diaz, J.; Adhikari, N.K.; Angus, D.C.; Arabi, Y.M.; Baillie, K.; Bauer, M.; Berry, S.; Blackwood, B.; et al. A minimal common outcome measure set for COVID-19 clinical research. Lancet Infect. Dis. 2020, 20, e192-e197. [CrossRef]

23. Jespersen, M.C.; Peters, B.; Nielsen, M.; Marcatili, P. BepiPred-2.0: Improving sequence-based B-cell epitope prediction using conformational epitopes. Nucleic Acids Res. 2017, 45, W24-W29. [CrossRef]

24. Ponomarenko, J.; Bui, H.-H.; Li, W.; Fusseder, N.; Bourne, P.E.; Sette, A.; Peters, B. ElliPro: A new structure-based tool for the prediction of antibody epitopes. BMC Bioinform. 2008, 9, 514. [CrossRef]

25. Wang, J.; Ji, J.; Ye, J.; Zhao, X.; Wen, J.; Li, W.; Hu, J.; Li, D.; Sun, M.; Zeng, H.; et al. The Structure Analysis and Antigenicity Study of the N Protein of SARS-CoV. Genom. Proteom. Bioinform. 2003, 1, 145-154. [CrossRef]

26. Poh, C.M.; Carissimo, G.; Wang, B.; Amrun, S.N.; Lee, C.Y.-P.; Chee, R.S.-L.; Fong, S.-W.; Yeo, N.K.-W.; Lee, W.-H.; Torres-Ruesta, A.; et al. Two linear epitopes on the SARS-CoV-2 spike protein that elicit neutralising antibodies in COVID-19 patients. Nat. Commun. 2020, 11, 2806. [CrossRef]

27. Zamecnik, C.R.; Rajan, J.V.; Yamauchi, K.A.; Mann, S.A.; Loudermilk, R.P.; Sowa, G.M.; Zorn, K.C.; Alvarenga, B.D.; Gaebler, C.; Caskey, M.; et al. ReScan, a Multiplex Diagnostic Pipeline, Pans Human Sera for SARS-CoV-2 Antigens. Cell Rep. Med. 2020, 1 , 100123. [CrossRef] [PubMed] 
28. Shrock, E.; Fujimura, E.; Kula, T.; Timms, R.T.; Lee, I.-H.; Leng, Y.; Robinson, M.L.; Sie, B.M.; Li, M.Z.; Chen, Y.; et al. Viral epitope profiling of COVID-19 patients reveals cross-reactivity and correlates of severity. Science 2020, 370, eabd4250. [CrossRef]

29. Ladner, J.T.; Henson, S.N.; Boyle, A.S.; Engelbrektson, A.L.; Fink, Z.W.; Rahee, F.; D'ambrozio, J.; Schaecher, K.E.; Stone, M.; Dong, W.; et al. Epitope-resolved profiling of the SARS-CoV-2 antibody response identifies cross-reactivity with an endemic human CoV. Immunology 2020, 2, 100189.

30. Yi, Z.; Ling, Y.; Zhang, X.; Chen, J.; Hu, K.; Wang, Y.; Song, W.; Ying, T.; Zhang, R.; Lu, H.; et al. Functional mapping of B-cell linear epitopes of SARS-CoV-2 in COVID-19 convalescent population. Emerg. Microbes Infect. 2020, 9, 1988-1996. [CrossRef] [PubMed]

31. Mishra, N.; Huang, X.; Joshi, S.; Guo, C.; Ng, J.; Thakkar, R.; Wu, Y.; Dong, X.; Li, Q.; Pinapati, R.; et al. Immunoreactive peptide maps of SARS-CoV-2 and other human coronaviruses. bioRxiv 2020. [CrossRef]

32. Klompus, S.; Leviatan, S.; Vogl, T.; Kalka, I.N.; Godneva, A.; Shinar, E.; Weinberger, A.; Segal, E. Cross-reactive antibody responses against SARS-CoV-2 and seasonal common cold coronaviruses. medRxiv 2020. [CrossRef]

33. Haynes, W.A.; Kamath, K.; Bozekowski, J.; Baum-Jones, E.; Campbell, M.; Casanovas-Massana, A.; Daugherty, P.S.; Dela Cruz, C.S.; Dhal, A.; Farhadian, S.F.; et al. High-resolution mapping and characterization of epitopes in COVID-19 patients. medRxiv 2020. [CrossRef]

34. Holenya, P.; Lange, P.J.; Reimer, U.; Woltersdorf, W.; Panterodt, T.; Glas, M.; Wasner, M.; Eckey, M.; Drosch, M.; Hollidt, J.-M.; et al. Peptide microarray based analysis of antibody responses to SARS-CoV-2 identifies unique epitopes with potential for diagnostic test development. medRxiv 2020. [CrossRef]

35. Heffron, A.S.; McIlwain, S.J.; Amjadi, M.F.; Baker, D.A.; Khullar, S.; Sethi, A.K.; Palmenberg, A.C.; Shelef, M.A.; O'Connor, D.H.; Ong, I.M. The landscape of antibody binding in SARS-CoV-2 infection. Immunology 2020, 19, e3001265. [CrossRef]

36. Zhang, X.; Wu, X.; Wang, D.; Lu, M.; Hou, X.; Wang, H.; Liang, T.; Dai, J.; Duan, H.; Xu, Y.; et al. Proteome-wide analysis of differentially-expressed SARS-CoV-2 antibodies in early COVID-19 infection. medRxiv 2020. [CrossRef]

37. Musicò, A.; Frigerio, R.; Mussida, A.; Barzon, L.; Sinigaglia, A.; Riccetti, S.; Gobbi, F.; Piubelli, C.; Bergamaschi, G.; Chiari, M.; et al. SARS-CoV-2 Epitope Mapping on Microarrays Highlights Strong Immune-Response to N Protein Region. Vaccines 2021,9 , 35. [CrossRef]

38. Premkumar, L.; Segovia-Chumbez, B.; Jadi, R.; Martinez, D.R.; Raut, R.; Markmann, A.; Cornaby, C.; Bartelt, L.; Weiss, S.; Park, Y.; et al. The receptor binding domain of the viral spike protein is an immunodominant and highly specific target of antibodies in SARS-CoV-2 patients. Sci. Immunol. 2020, 5, eabc8413. [CrossRef]

39. Gallo Marin, B.; Aghagoli, G.; Lavine, K.; Yang, L.; Siff, E.J.; Chiang, S.S.; Salazar-Mather, T.P.; Dumenco, L.; Savaria, M.C.; Aung, S.N.; et al. Predictors of COVID-19 severity: A literature review. Rev. Med. Virol. 2021, 31, 1-10. [CrossRef]

40. Chidambaram, V.; Tun, N.L.; Haque, W.Z.; Majella, M.G.; Sivakumar, R.K.; Kumar, A.; Hsu, A.T.-W.; Ishak, I.A.; Nur, A.A.; Ayeh, S.K.; et al. Factors associated with disease severity and mortality among patients with COVID-19: A systematic review and meta-analysis. PLoS ONE 2020, 15, e0241541. [CrossRef]

41. Williamson, E.J.; Walker, A.J.; Bhaskaran, K.; Bacon, S.; Bates, C.; Morton, C.E.; Curtis, H.J.; Mehrkar, A.; Evans, D.; Inglesby, P.; et al. Factors associated with COVID-19-related death using OpenSAFELY. Nature 2020, 584, 430-436. [CrossRef]

42. Carrillo, J.; Izquierdo-Useros, N.; Ávila-Nieto, C.; Pradenas, E.; Clotet, B.; Blanco, J. Humoral immune responses and neutralizing antibodies against SARS-CoV-2; implications in pathogenesis and protective immunity. Biochem. Biophys. Res. Commun. 2021, 538, 187-191. [CrossRef]

43. Chan, J.F.-W.; Kok, K.-H.; Zhu, Z.; Chu, H.; To, K.K.-W.; Yuan, S.; Yuen, K.-Y. Genomic characterization of the 2019 novel human-pathogenic coronavirus isolated from a patient with atypical pneumonia after visiting Wuhan. Emerg. Microbes Infect. 2020, 9, 221-236. [CrossRef] [PubMed]

44. Zhang, Y.; Chen, Y.; Li, Y.; Huang, F.; Luo, B.; Yuan, Y.; Xia, B.; Ma, X.; Yang, T.; Yu, F.; et al. The ORF8 protein of SARS-CoV-2 mediates immune evasion through down-regulating MHC-I. Proc. Natl. Acad. Sci. USA 2021, 118, e2024202118. [CrossRef] [PubMed]

45. Arvin, A.M.; Fink, K.; Schmid, M.A.; Cathcart, A.; Spreafico, R.; Havenar-Daughton, C.; Lanzavecchia, A.; Corti, D.; Virgin, H.W. A perspective on potential antibody-dependent enhancement of SARS-CoV-2. Nature 2020, 584, 353-363. [CrossRef] [PubMed]

46. Lee, W.S.; Wheatley, A.K.; Kent, S.J.; DeKosky, B.J. Antibody-dependent enhancement and SARS-CoV-2 vaccines and therapies. Nat. Microbiol. 2020, 5, 1185-1191. [CrossRef] [PubMed] 